\title{
Identification of novel EIF2B mutations in Chinese patients with vanishing white matter disease
}

\author{
Ye $\mathrm{Wu}^{1,3}$, Yanxia Pan ${ }^{1,2,3}$, Li Du ${ }^{1,2}$, Jingmin Wang ${ }^{1}$, Qiang Gu ${ }^{1}$, Zhijie Gao ${ }^{1,2}$, Jie $\mathrm{Li}^{1,2}$, Xuerong Leng ${ }^{1}$, \\ Jiong Qin ${ }^{1}$, Xiru $\mathrm{Wu}^{1}$ and Yuwu Jiang ${ }^{1}$
}

\begin{abstract}
Vanishing white matter (VWM) disease, inherited in an autosomal recessive manner, is one of the most prevalent inherited leukoencephalopathies in childhood. It is a hereditary human disease resulting from the direct defects during protein synthesis, with the gene defects in EIF2B1-5 (identified in 2001-2002) encoding the five subunits of eukaryotic translation initiation factor (elF2B $\alpha, \boldsymbol{\beta}, \gamma, \delta$ and $\varepsilon$ ), respectively. Most of the published studies were carried out in the white population. The analysis of clinical features and EIF2B mutation screening were performed in 11 Chinese patients for the first time. Mutations were identified exclusively in EIF2B5 and EIF2B3 in these patients, with six novel mutations, including five missense mutations (EIF2B5: c.185A > T, p.D62V; c.1004G > C, p.C335S; c.1126A > G, p.N376D; EIF2B3: c.140G >A, p.G47E; c.1037T >C, p.1346T) and one deletion leading to amino-acid deletion (EIF2B5: c.1827-1838del, p.S610-D613del). EIF2B3 mutation, accounting for $20 \%$ of the total number of mutations found in this study, is more prevalent than expected according to an earlier report (7\%). A hot spot mutation in EIF2B3 was identified in this study. A unique EIF2B mutation spectrum in Chinese VWM patients was shown. A systemic study to assess mutation spectrum in different populations needs to be carried out. Journal of Human Genetics (2009) 54, 74-77; doi:10.1038/jhg.2008.10; published online 16 January 2009
\end{abstract}

Keywords: Chinese; EIF2B; elF2B; mutation; vanishing white matter (VWM) disease

\section{INTRODUCTION}

Vanishing white matter (VWM, OMIM 306896) disease, also known as leukoencephalopathy with VWM or childhood ataxia with central nervous system hypomyelination, is one of the most prevalent inherited leukoencephalopathies in childhood. ${ }^{1}$ The phenotype varies highly, from severe antenatal form with onset in the third trimester of pregnancy, to the milder variant with onset in adulthood. ${ }^{2,3}$ The most common age of onset is in early childhood, at 2-6 years of age. Patients with classical phenotype usually present progressive neurological deterioration, with mental abilities preserved better than motor functions. Typically, there are episodes of rapid deterioration provoked by mild head trauma, febrile infection or fright. Patients can survive from the episodes with incomplete recovery or end with death. Death usually occurs at $2-5$ years after disease onset in early childhood. The features of cranial magnetic resonance imaging (MRI) are unique, which is very helpful to the clinical diagnosis of VWM. MRI typically shows gradual disappearance of cerebral white matter with replacement by fluid. ${ }^{1}$

VWM, inherited in an autosomal recessive manner, is a hereditary human disease resulting from the direct defects during protein synthesis. The disease-causing gene defects were identified in 20012002. Mutations in EIF2B1-5, encoding the five subunits of eukaryotic translation initiation factor (eIF2B $\alpha, \beta, \gamma, \delta$ and $\varepsilon$ ), respectively, were found in VWM patients. ${ }^{4,5}$ eIF2B, along with some other eIFs, plays key roles in the initiation of protein translation in all eukaryotic cells. Since 2001, more than 120 mutations in EIF2B1-5 have been identified. ${ }^{6}$ Most of the published studies were carried out in the white population. Chinese patients with genetic confirmative diagnosis of VWM have never been reported before. In this study, we analyzed 11 Chinese patients, and seven novel mutations in eIF $2 B$ were identified.

\section{MATERIALS AND METHODS}

Diagnostic criteria of VWM

The clinical diagnosis was mainly based on the criteria proposed by van der Knaap et al., ${ }^{7}$ including the following. (1) Early psychomotor development is usually normal or mildly delayed. (2) The clinical presentation is early-childhood onset of neurological regression with episodic and chronic progressive course. Mental abilities are relatively better preserved than motor functions. The episodes may follow infection or minor head trauma. (3) Neurological signs mainly consist of cerebellar ataxia and spasticity. (4) Cranial MRI shows a symmetrical signal similar to cerebrospinal fluid on T1-weighted, T2-weighted and flair images in part or all of cerebral white matter. Eleven patients who met the criteria were included.

Clinical investigations

All patients underwent extensive clinical investigations, including: (1) physical examinations; (2) blood tests for serum level of electrolytes, ammonia, lactate 
and pyruvate, as well as assessment of liver and renal functions; (3) assessment of enzyme activity of arylsulfatase $A$ and galactocerebroside $\beta$-galactosidase in peripheral white blood cells; (4) urinary screening for metabolic disorder of amino acids, organic acids and fatty acids; and (5) cranial MRI.

\section{DNA preparation and mutation screening}

Informed consent was obtained from all the families tested. Genomic DNA was extracted from peripheral leukocytes. To our knowledge, among the 120 reported mutations, 57\% were identified in EIF2B5 (encoding eIF2BE), 16\% in EIF2B4 (encoding eIF2B $)$ ), $16 \%$ in EIF2B2 (encoding eIF2Bß), $7 \%$ in EIF2B3 (encoding eIF2B $\gamma$ ) and $4 \%$ in EIF2B1 (encoding eIF2B $\alpha$ ). ${ }^{8} 9$ Thus, mutation screening for EIF2B5 was carried out first in each patient, followed by screening for EIF2B4, EIF2B2, EIF2B3 and EIF2B1. In total, 16 exons of EIF2B5, 13 exons of EIF2B4, 8 exons of EIF2B2, 12 exons of EIF2B3 and 9 exons of EIF2B1, including flanking introns, were amplified. The sequences of the primers and the conditions for PCR are available on request. DNA sequencing was carried out using ABI PRISM Bigdye Terminator Cycle Sequencing Ready Reaction Kit (Applied Biosystems) on an applied Biosystems 3100 automatic DNA sequencer. For novel mutations found in patients, the corresponding amplicons from 100 control samples were amplified, followed by sequencing and restriction endonuclease reactions.

\section{RESULTS}

\section{Clinical features of Chinese VWM patients}

These unrelated patients, consisting of eight boys and three girls, came from 11 core families. All individuals were free of symptoms at birth and their developmental milestones were normal or mildly delayed. The symptoms began to appear between 1.5 years and 6 years of age, usually with subacute onset. The initial presentation was deterioration of motor coordination or unstable gait in all but one case; the exception was patient 5 , in whom afebrile seizure was the initial symptom. The neurological deterioration gradually progressed in all the 11 cases, with episodic aggravation in 6 cases. After 9 months, that is, $\sim 7$ years from disease onset, mild to severe motor handicap gradually developed, with cognitive function relatively better preserved. Six patients had occasional seizures during the course. Physical examinations showed spasticity and symmetric pyramidal tract signs. All individuals were children of non-consanguineous parents. Family history was negative in all but one patient (patient 3), whose older sister, with unstable gait and several seizure attacks after 1 year of age, died after an acute upper respiratory tract infection at 2 years of age. The cranial MRI showed symmetric and diffuse abnormal signal in periventricular white matter in all cases, with a part having signal intensity close to cerebrospinal fluid on T1-weighted, T2-weighted and flair images (Figure 1). Signal abnormalities in regions other than cerebral white matter were shown in some of the patients: two cases in brainstem, one case in thalamus and two cases in cerebellar white matter. All the other clinical investigations were unrevealing. The major clinical features of these patients are summarized in Table 1.

\section{EIF2B1-5 mutation screening analysis}

Mutations were identified exclusively in EIF2B5 and EIF2B3 in these patients (Table 1), consisting of six novel and nine mutations reported earlier. EIF2B5 mutations were found in six patients and EIF2B3 mutations in five. Six novel mutations, including five missense mutations (EIF2B5: c.185A >T, p.D62V; c.1004G >C, p.C335S; c.1126A > G, p.N376D; EIF2B3: c.140G >A, p.G47E; c.1037T >C, p.I346T) and one deletion leading to amino-acid deletion (EIF2B5: c.1827-1838del, p.S610-D613del), were not identified in 100 normal control samples. Patients were compound heterozygous or homozygous, with the mutations inherited from their parents with normal phenotype. In one patient, mutation was identified only in one allele (patient 10).

\section{DISCUSSION}

VWM is one of the most prevalent inherited leukoencephalopathies in childhood. The previous studies showed that this disease seems to be particularly common in white populations, but the information of the difference in incidence among variant populations is currently unavailable, ${ }^{1}$ probably because fewer studies have been carried out in people other than the white population. According to the age of disease onset and the rate of progression, VWM can be clinically categorized into classical phenotype and phenotype variations (consisting of milder variants with adolescent or adult onset, and severe phenotype with early infantile or antenatal onset). ${ }^{1-3,10}$ All the 11 Chinese patients who met the criteria proposed by van der Knaap et al. in this study had the classical phenotype. The classical phenotype is the most common in VWM, with onset at 2-6 years of age. The typical presentation is deteriorated motor function (ataxia and spasticity) followed by progressive regression, usually with episodic aggravation provoked by fever or head trauma. Mental abilities are relatively better preserved. The episode may end with coma and even death, or with incomplete recovery. Patients usually die in a few years after disease onset. Epilepsy is common during the disease course, but usually mild. ${ }^{1,2,11}$ All the patients in this study showed the typical clinical features, and at the most recent follow-up it was found that
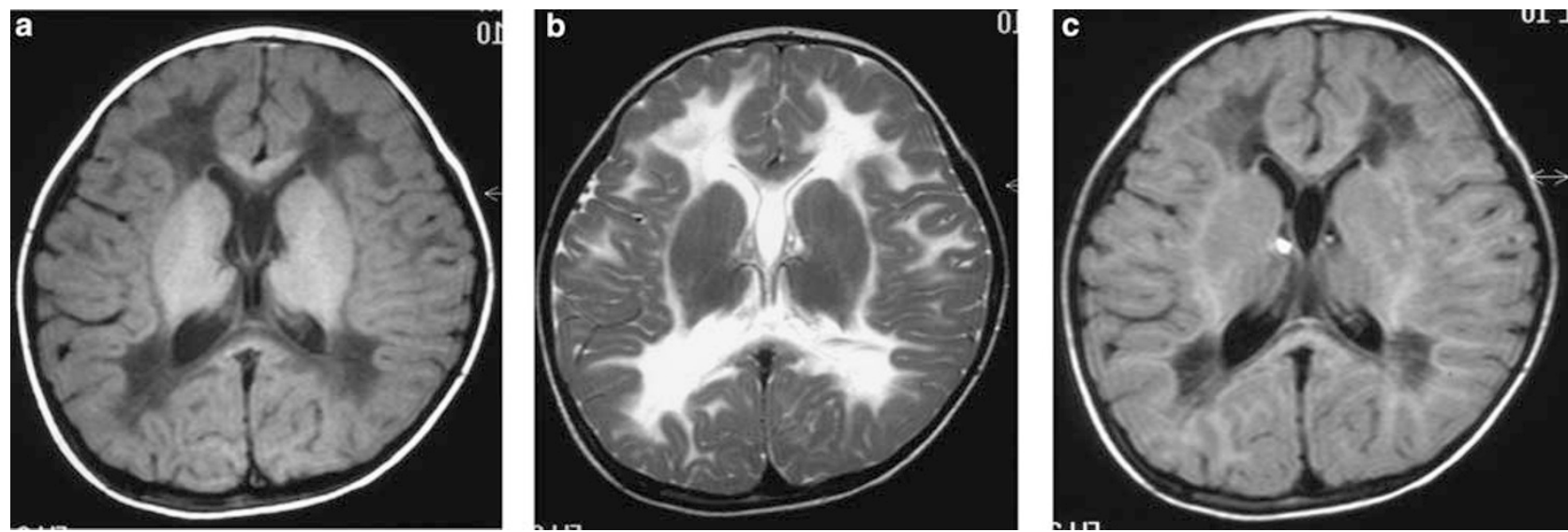

Figure 1 Cranial MRI of patient 7. Symmetric and diffuse signal abnormalities in periventricular and deep cerebral white matter are shown, with low signals in T1-weighted image (a) and flair image (c), and high signals in T2-weighted image (b), similar to those for cerebrospinal fluid. 
Table 1 Clinical data and EIF2B mutations in 11 VWM patients

\begin{tabular}{|c|c|c|c|c|c|c|c|c|c|c|c|c|c|c|}
\hline \multirow[b]{2}{*}{ Patient } & \multirow[b]{2}{*}{ Gender } & \multirow[b]{2}{*}{$\begin{array}{l}\text { Developmental } \\
\text { milestone before } \\
\text { disease onset }\end{array}$} & \multicolumn{2}{|c|}{ Disease onset } & \multicolumn{3}{|c|}{ Disease progression } & \multirow[b]{2}{*}{$\begin{array}{l}\text { Family } \\
\text { history }\end{array}$} & \multicolumn{6}{|c|}{ EIF2B mutations } \\
\hline & & & $\begin{array}{l}\text { Age of } \\
\text { disease } \\
\text { onset }\end{array}$ & $\begin{array}{l}\text { Initial } \\
\text { symptoms }\end{array}$ & $\begin{array}{l}\text { Age at } \\
\text { last } \\
\text { follow-up }\end{array}$ & $\begin{array}{l}\text { Major } \\
\text { symptoms }^{\mathrm{a}}\end{array}$ & $\begin{array}{l}\text { Disease } \\
\text { course }^{\mathrm{b}}\end{array}$ & & Gene & Exon & $\begin{array}{l}\text { Nucleotide } \\
\text { change }\end{array}$ & $\begin{array}{l}\text { Amino-acid } \\
\text { change }\end{array}$ & $\begin{array}{l}\text { Novel/ } \\
\text { reported }\end{array}$ & $\begin{array}{l}\text { Parental } \\
\text { derivation }\end{array}$ \\
\hline 1 & Male & Mildly delayed & $1 \mathrm{y} 10 \mathrm{~m}$ & Motor signs & $4 y 4 m$ & M3, C2, S, D & $P$ & - & EIF2B5 & 7,7 & $\begin{array}{l}\text { c. } 943 \mathrm{C}>\mathrm{T} \\
\text { c. } 943 \mathrm{C}>\mathrm{T}\end{array}$ & $\begin{array}{l}\text { p.R315C } \\
\text { p.R315C }\end{array}$ & $\begin{array}{l}\text { Reported } \\
\text { Reported }\end{array}$ & $\begin{array}{l}\text { Mother } \\
\text { Father }\end{array}$ \\
\hline 3 & Female & Mildly delayed & $2 y$ & Motor signs & $9 y 4 m$ & $\mathrm{M} 3, \mathrm{C} 1, \mathrm{~S}, \mathrm{D}$ & $P+E$ & + & EIF2B5 & 6,7 & $\begin{array}{l}\text { c. } 805 \mathrm{C}>\mathrm{T} \\
\text { c. } 1004 \mathrm{G}>\mathrm{C}\end{array}$ & $\begin{array}{l}\text { p.R269X } \\
\text { p.C335S }\end{array}$ & $\begin{array}{l}\text { Reported } \\
\text { Novel }\end{array}$ & $\begin{array}{l}\text { Mother } \\
\text { U }\end{array}$ \\
\hline 4 & Male & Normal & $6 y 8 m$ & Motor signs & $8 y 3 m$ & $\mathrm{M} 1, \mathrm{CO}, \mathrm{S}$ & $P$ & - & EIF2B5 & 1,7 & $\begin{array}{l}\text { c. } 185 \mathrm{~A}>\mathrm{T} \\
\text { c. } 1016 \mathrm{G}>\mathrm{C}\end{array}$ & $\begin{array}{l}\text { p.D62V } \\
\text { p.R339P }\end{array}$ & $\begin{array}{l}\text { Novel } \\
\text { Reported }\end{array}$ & $\begin{array}{l}\text { Father } \\
\text { Mother }\end{array}$ \\
\hline 5 & Male & Normal & $4 y 6 m$ & Seizure & $5 y 11 m$ & M2, C1, S, D & $P$ & - & EIF2B5 & 8,13 & $\begin{array}{l}\text { c. } 1157 \mathrm{G}>\mathrm{T} \\
\text { c.1827- } \\
1838 \mathrm{del}\end{array}$ & $\begin{array}{l}\text { p.G386V } \\
\text { p.S610- } \\
\text { D613del }\end{array}$ & $\begin{array}{l}\text { Reported } \\
\text { Novel }\end{array}$ & $\begin{array}{l}\text { Mother } \\
U\end{array}$ \\
\hline 8 & Male & Normal & $3 y 9 m$ & Motor signs & $5 y 6 m$ & M2, C1 & $P+E$ & - & EIF2B3 & 9,9 & $\begin{array}{l}\text { c. } 1037 \mathrm{~T}>\mathrm{C} \\
\mathrm{c} .1037 \mathrm{~T}>\mathrm{C}\end{array}$ & $\begin{array}{l}\text { p.1346T } \\
\text { p.1346T }\end{array}$ & $\begin{array}{l}\text { Novel } \\
\text { Novel }\end{array}$ & $\begin{array}{l}\text { Father } \\
U\end{array}$ \\
\hline 9 & Male & Normal & $5 y 1 \mathrm{~m}$ & Motor signs & $6 y 4 m$ & $\mathrm{M} 2, \mathrm{CO}$ & $P$ & - & EIF2B3 & 7,7 & $\begin{array}{l}\text { c. } 674 G>A \\
\text { c. } 674 G>A\end{array}$ & $\begin{array}{l}\text { p.R225Q } \\
\text { p.R225Q }\end{array}$ & $\begin{array}{l}\text { Reported } \\
\text { Reported }\end{array}$ & $\begin{array}{l}\text { Mother } \\
\text { Father }\end{array}$ \\
\hline 10 & Male & Mildly delayed & $1 \mathrm{y} 6 \mathrm{~m}$ & Motor signs & $3 y$ & M3, C1 & $P$ & - & EIF2B3 & 9, ND & $\begin{array}{l}\text { c. } 1037 \mathrm{~T}>\mathrm{C} \\
\mathrm{ND}\end{array}$ & $\begin{array}{l}\text { p.1346T, } \\
\text { ND }\end{array}$ & Novel & Mother \\
\hline 11 & Male & Normal & $4 y 3 m$ & Motor signs & $5 y 2 m$ & $\mathrm{M} 1, \mathrm{CO}$ & $P+E$ & - & EIF2B3 & 9,9 & $\begin{array}{l}\text { c. } 1037 \mathrm{~T}>\mathrm{C} \\
\text { c. } 1037 \mathrm{~T}>\mathrm{C}\end{array}$ & $\begin{array}{l}\text { p.I346T } \\
\text { p.I346T }\end{array}$ & $\begin{array}{l}\text { Novel } \\
\text { Novel }\end{array}$ & $\begin{array}{l}\text { Mother } \\
\text { Father }\end{array}$ \\
\hline
\end{tabular}

Abbreviations: CO, no cognitive handicap; C1, mild cognitive handicap (mild learning and language difficulty); C2, moderate cognitive handicap (obvious learning and language difficulty, still able to communicate with others); C3, severe cognitive handicap (severe learning and language difficulty, lost of communication with others); D, dysarthria; E, episodic aggravation; M0, no motor handicap; M1, mild motor handicap (ataxia or gait difficulty, ambulate without assistant); M2, moderate motor handicap (ambulate with assistant); M3, severe motor handicap (wheelchair bound or confined to bed); m, month; ND, not identified; $\mathrm{P}$, progressive; $\mathrm{P}+\mathrm{E}$, progressive with episodic aggravation; $\mathrm{S}$, seizures; $\mathrm{U}$, unavailable; VWM, vanishing white matter; $\mathrm{y}$, year; +, positive; -, negative.

a Major symptoms.

bisease course.

they had survived the disease course from 9 months to 7 years. The rarefaction and cystic degeneration in cerebral white matter in cranial MRI, the hallmark in VWM, were shown in all our patients. Signal abnormalities may also be seen in cerebellar white matter, brainstem, thalamus or globus pallidus in cranial MRI from VWM patients. ${ }^{1}$

Mutations in EIF2B1-5, encoding the five subunits of eukaryotic translation initiation factor (eIF2B $\alpha, \beta, \gamma, \delta$ and $\varepsilon$ ), respectively, were found in VWM patients in 2001-2002. eIF2B plays an essential role in the initiation of protein translation in all eukaryotic cells. During the initiation process, eIF2, when bound to guanosine 5'-triphosphate (GTP), forms a ternary complex with the initiator methionyl-tRNA, delivers the methionyl-tRNA to the small ribosome subunit (40S) and recognizes the AUG start codon. After that, the hydrolysis of GTP to GDP (guanosine 5'-diphosphate) occurs, followed by the release of eIF2-GDP from the ribosome. To initiate the next round of translations, eIF2-bound GDP must be replaced by GTP; in this process, eIF2B subunits catalyze the exchange of GDP with GTP. ${ }^{16}$ The pathogenic mechanisms of VWM due to eIF2B gene defects are far from well understood; the aberrant translation of some protein with upstream open reading frames in mRNA, such as activating transcription factor (ATF)4, and activation of unfolded-protein response (UPR) in ER are believed to be involved. ${ }^{12-15}$

eIF2B is a complex of five subunits. eIF2Be (encoded by EIF2B5), possessing the guanine nucleotide-exchanging factor (GEF) activity to catalyze the eIF2-bound GDP-GTP exchange, is the most important subunit. The other subunits play key roles in the regulation of GEF activity of eIF2Be. The GEF activity of the five-subunits holocomplex is $10-40$-fold of that from eIF2B $\varepsilon$ alone. eIF2B $\varepsilon$ is a 721 -amino-acid protein. It was found that the C-terminal residues (518-712) of eIF2B $\varepsilon$ contained a minimal functional unit that interacts with eIF2 and GDP-GTP exchange, with residues 581-712 interacting with eIF2 and 518-580 for GEF activity. The N-terminal about 500 residues probably interacts with other eIF2B subunits. ${ }^{16}$ More than 60 eIF2B $\varepsilon$ mutations were reported in VWM patients, and it was found that relatively few mutations were in and around the catalytic function unit compared with the N-terminal. ${ }^{8}$ In our study, five novel eIF2B5 mutations were found. Three missense mutations, p.D62V, p.C335S and p.N376D, which occurred in the N-terminal, may interrupt the interaction between $\mathrm{eIF} 2 \mathrm{~B} \varepsilon$ and other subunits. S610-D613del results in a fouramino-acid deletion in the C-terminal, which may affect the interaction with eIF2 and the GEF activity. Among the five residues affected by EIF2B5 and EIF2B3 missense mutations found in our study, four are conserved in variant vertebrates during evolution, with p.C335S being less conserved (Table 2). Further study is needed to provide insight into the effects of mutations on functions of eIF2B complex.

So far, there are more than 120 mutations reported in $\mathrm{VWM},{ }^{6}$ with more than half identified in EIF2B5 (57\%), followed by EIF2B4 (16\%), EIF2B2 (16\%), EIF2B3 (7\%) and EIF2B1 (4\%). About $65 \%$ of reported patients harbor mutations in EIF2B5. p.R113H in EIF2B5 is reported to be a hot-spot mutation, which occurs in almost $40 \%$ of 
Table 2 Evolutionary conservation of five novel EIF2B missense mutations identified in Chinese VWM patients

\begin{tabular}{|c|c|c|c|c|c|}
\hline & EIF2B5 & EIF2B5 & EIF2B5 & EIF2B3 & EIF2B3 \\
\hline & D62V & C335S & N376D & G47E & I346T \\
\hline Homo sapiens & SKDQP & QSCTH & ITNSV & RVGFE & AQIVS \\
\hline Rattus norvegicus & 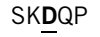 & QSYYTH & ITNSVV & RVGGFE & AQIAN \\
\hline Mus musculus & SKDQQP & QSYYTH & ITNSV & RVGFE & AQIVN \\
\hline Zebrafish & TKDQPP & QSCITH & ISNTTV & RVGGFE & AVV $\underline{\text { SE }}$ \\
\hline Drosophila melanogaster & SDEGGS & QEYYVF & ISDSV & QHNFT & GAVVK \\
\hline Saccharomyces cerevisiae & TAVKP & QTYSY & IENSV & QADFK & $N|Q| Q$ \\
\hline
\end{tabular}

Abbreviation: VWM, vanishing white matter.

The underlined amino acids in bold type correspond to positions of interest.

VWM patients. ${ }^{8,17,18}$ However, in this study on Chinese patients, a spectrum of EIF2B mutations different from that in the earlier report was shown. Mutations were identified exclusively in EIF2B5 and EIF2B3 in these 11 patients, with 5 having EIF2B3 mutations. EIF2B3 mutation accounts for $20 \%(3 / 15)$ of the total number of mutations found in this study; it is possible that in Chinese patients there is a higher frequency of mutations in EIF2B3. A hot-spot mutation in EIF2B3 was identified in this study, with four of five patients having p.I346T mutation. The earlier reported hot-spot mutation, p.R113H in EIF2B5, was not identified in any of our patients. Therefore, from our preliminary data, it may be inferred that Chinese VWM patients may have a unique spectrum of EIF2B mutations, which is different from that of the white population and is helpful to set up the mutation-screening strategy for VWM in China. More patients need to be recruited for further analysis.

Chinese VWM patients with genetic confirmation are reported for the first time, with six novel mutations in EIF2B5 and EIF2B3 identified. A unique EIF2B mutation spectrum in Chinese patients was shown. To assess the incidence of VWM and mutation spectrum in different populations, a systemic study needs to be carried out. Further functional studies are needed to delineate the correlation between the EIF2B gene defect and the pathogenesis of VWM.

\section{ACKNOWLEDGEMENTS}

We are grateful to the patients' families. This study was funded by the National Key Research Project '11-5' (2006BAI05A07), National Key Research Project
'973' (2007CB5119004), Natural Science Foundation of China (30772355, 30872793) and Natural Science Foundation of Beijing (7082093, 7081004).

1 van der Knaap, M. S., Pronk, J. C. \& Scheper, G. C. Vanishing white matter disease. Lancet Neurol. 5, 413-423 (2006).

2 van der Knaap, M. S., Kamphorst, W., Barth, P. G., Kraaijeveld, C. L., Gut, E. \& Valk, J. Phenotypic variation in leukoencephalopathy with vanishing white matter. Neurology 51, 540-547 (1998)

3 van der Knaap, M. S., van Berkel, C. G. M., Herms, J., van Coster, R., Baethmann, M. \& Naidu, S. et al. elF2B related disorders: antenatal onset and involvement of multiple organs. Am. J. Hum. Genet. 73, 1199-1207 (2003).

4 Leegwater, P. A., Vermeulen, G., Konst, A. A. M., Naidu, S., Mulder, J. \& Visser, A. et al. Subunits of translation initiation factor elF2B are mutant in leukoencephalopathy with vanishing white matter. Nat. Genet. 29, 383-388 (2001).

5 Leegwater, P. A., Pronk, J. C. \& van der Knaap, M. S. Leukoencephalopathy with vanishing white matter: from magnetic resonance imaging patter to five genes. J. Child Neurol. 18, 639-645 (2003).

6 Maletkovic, J., Schiffmann, R., Gorospe, J. R., Gordon, E. S., Mintz, M. \& Hoffman, E. P. et al. Genetic and clinical heterogeneity in elF2B-related disorder. J. child Neurol. 23, 205-215 (2008)

7 van der Knaap, M. S., Barth, P. G., Gabreels, F. J. M., Franzoni, E., Begeer, J. H. \& Stroink, H. et al. A new leukoencephalopathy with vanishing white matter. Neurology 48, 845-855 (1997).

8 Pronk, J. C., van Kollenburg, B., Scheper, G. C. \& van der Knaap, M. S. Vanishing white matter disease: a review with focus on its genetics. Ment. Retard. Dev. Disabil. Res. Rev. 12, 123-128 (2006).

9 Fogli, A. \& Boespflug-Tanguy, O. The large spectrum of elF2B-related disease. Biochem. Soc. Trans. 34, 22-29 (2006).

10 Riecker, A., Nagele, T., Henneke, M. \& Scholes, L. Late onset vanishing white matter disease. J. Neurol. 254, 544-545 (2007).

11 Scali, O., Perri, C. D. \& Federico, A. The spectrum of mutations for the diagnosis of vanishing white matter disease. Neurol. Sci. 27, 271-277 (2006).

12 Kantor, L., Harding, H. P., Ron, D., Schiffmann, R., Kaneski, C. R. \& Kimball, S. R. et al. Heightened stress response in primary fibroblasts expressing mutant elF2B genes from CACH/VWM leukodystrophy patients. Hum. Genet. 118, 99-106 (2005).

13 Kubica, N., Jefferson, L. S. \& Kimball, S. R. Eukaryotic initiation factor $2 B$ and its role in alterations in mRNA translation that occur under a number of physiological and physiological conditions. Prog. Nucleic Acid Res. Mol. Biol. 81, 271-296 (2006).

14 van Kollenburg, B., van Dijk, J., Garbern, J., Thomas, A. A. M., Scheper, G. C. \& Powers, J. M. et al. Glia-specific activation of all pathways of the unfolded protein response in vanishing white matter disease. J. Neuropathol. Exp. Neurol. 65, 707-715 (2006).

15 Scheper, G. C., Proud, C. G. \& van der Knaap, M. S. Defective translation initiation causes vanishing of cerebral white matter. Trends Mol. Med. 12, 159-166 (2006).

16 Pavitt, G. D. elF2B, a mediator of general and gene-specific translational control. Biochem. Soc. Trans. 33, 1487-1492 (2005).

17 Ohlenbusch, A., Henneke, M., Brockmann, K., Goerg, M., Hanefeld, F. \& Kohlshutter, A. et al. Identification of ten novel mutations in patients with elF2B-related disorder. Hum. Mutat. 25, 411 (2005).

18 Matsui, M., Mizutani, K., Ohtake, H., Miki, Y., Ishizu, K. \& Fukuyama, H. et al. Novel mutations in EIF2B gene in a case of adult-onset leukoencephalopathy with vanishing white matter. Eur. Neurol. 57, 57-58 (2007). 